\title{
The railway superstructure monitoring in bratislava tunnel no. 1 - section of ballastless track and its transition areas
}

\author{
Libor Izvolt $^{1,}$, Janka Sestakova $^{{ }^{*}}$, and Michal Smalo ${ }^{1}$ \\ ${ }^{1}$ University of Zilina, Faculty of Civil Engineering, Department of Railway Engineering and Track \\ Management, Univerzitna 8215/1, 01026 Zilina, Slovak Republic
}

\begin{abstract}
The requirements for the quality of the railway track with emphasis on its long service life, low maintenance costs and the required parameters of the track geometry have led railway infrastructure manager on the territory of the Slovak Republic - Zeleznice Slovenskej republiky (ZSR) - to modernize or to realize reconstructions of railway lines on the appropriate track sections with the application of the unconventional construction of the railway superstructure (ballastless track). The Department of Railway Engineering and Track Management currently performs the monitoring of two sections with the application of ballastless track construction. This paper is aimed to the monitoring of the ballastless track section and presents the results obtained so far in one of the monitored sections in the Bratislava tunnel No. 1.
\end{abstract}

\section{Introduction}

The ballastless track has become a standard construction for a railway superstructure on some sections of the modernized railway infrastructure of Railways of Slovak Republic (Zeleznice Slovenskej republiky - ZSR). The ZSR network has its application in some new constructions of bridges and tunnels. Supposed service life, easier and less costly maintenance, and thinner structural thickness in comparison with ballasted track construction, define the progressive use of a ballastless track even for more extensive reconstruction of these objects. The design and operating principles and advantages of a ballastless track compared to ballasted track have already been characterized in [1] and [2].

Within the framework of the cooperation of the Department of Railway Engineering and Track Management (KZSTH) of the Faculty of Civil Engineering of the University of Zilina with the ZSR, monitoring of two experimental sections is currently being carried out, in the tunnel Turecky vrch and around the tunnel portals (in four subsections of a total length 1.640 meters of track is monitored) and in the Bratislava tunnel No. 1 and around its portals (647 m long section).

Diagnostics by continuous monitoring and evaluation of its results, which were obtained by measurements in Bratislava tunnel No. 1 between 2015 and 2017 will be further characterized.

*Corresponding author: janka.sestakova@,fstav.uniza.sk 


\section{Experimental Section in Bratislava Tunnel No. 1}

The track section, which is the subject of track diagnostics, is located in track No. 1 from $\mathrm{km} 53.063$ to $\mathrm{km} 53.710$ of double-track railway line Devinska Nova Ves - Sturovo. The construction of the railway superstructure was built during the reconstruction of the singletrack tunnel in 2014 and consists of ballasted track, ballastless track of the prefabricated $O ̈ B B-P O R R$ slab system and the transition area between these structures. The construction of the railway superstructure of the section is described in detail in [3].

\section{Monitoring of the Experimental Section}

Experimental section is monitored since 2015 with aim of track geometry quality diagnostics. Monitoring is carried out by the measuring trolley $\mathrm{KRAB}^{\mathrm{TM}}$-Light with continuous data recording system:

- gauge tolerance RK (after calculating the change of gauge ZR is also recorded),

- alignment of right rail SP (after calculating the alignment of left rail SL is also recorded),

- $\quad$ rail top level of right rail VP (after calculating the rail top level of left rail VL is also recorded),

- cant PK,

- quasi-twist on a short base (calculated to a quasi-twist on a base of $3.0 \mathrm{~m}$ long $-\mathrm{ZK}_{3.0}$, $6.0 \mathrm{~m}$ long $-\mathrm{ZK}_{6.0}$ and $12.0 \mathrm{~m}$ long $-\mathrm{ZK}_{12.0}$ ),

- distance,

- measuring device velocity.

The diagnostics of the track geometry was carried out on semi-annual basis as:

- measurements before putting sections into operation (MSO) 29. 4. 2015,

- first operational measurement (PO1) 22. 10. 2015,

- second operational measurement (PO2) 11. 4. 2016,

- third operational measurement (PO3) 11. 10. 2016,

- fourth operational measurement (PO4) 6. 4. 2017.

\section{Evaluation of Measurements}

In the track, the measured data (their primary values) are recorded on the on-board computer PDA-TDS NOMAD. The onboard computer program allows reading and storing values in a data file with a step of $0.25 \mathrm{~m}$. Subsequent processing of values of geometric quantities obtained by measurement is carried out in the KRAB 8.1 program, from a set of primary data (.krx). After editing the evaluation parameters (description of the evaluated section, assignment of the track geometry parameters values, speed range and evaluation limits), the track geometry parameters are calculated by transforming the primary values. These resulting values, taking into account the dynamic component of measurement, are the basis for assessing the track geometry quality of the section in the form of:

- local errors table with sections where the sections with exceedances of the allowed variations of the individual variables are highlighted,

- section evaluation table containing standard tolerances of variables (SDV), quality marks $(\mathrm{QM})$ and quality number of evaluated section (QN),

- graph of track geometry parameters and values of permissible deviations.

Experimental section is assigned to speed zone 1 (RP1) according to line speed $(\mathrm{V}=60 \mathrm{kmph}$ ) [4]. Section is defined as straight line with a short curve of large radius $\mathrm{R}=2000 \mathrm{~m}$ in area of Lamac portal. Section was evaluated against allowed deviations, resp. against allowed values (table 1) for speed zone 1 for straight line (limited allowed deviations for parameter RK evaluated according to operational diagnostics). 
Table 1. The deviations of the relative geometric parameters of the track for RP1. [5, 6]

\begin{tabular}{|c|c|c|c|c|c|c|c|c|}
\hline Measured parameter & \multicolumn{2}{|c|}{$\begin{array}{l}\text { Limit input } \\
\text { deviations }\end{array}$} & \multicolumn{2}{|c|}{$\begin{array}{c}\text { Operational } \\
\text { deviations (AL) }\end{array}$} & \multicolumn{2}{|c|}{$\begin{array}{c}\text { Operational } \\
\text { deviations (IL) }\end{array}$} & \multicolumn{2}{|c|}{$\begin{array}{l}\text { Limit operational } \\
\text { deviations (IAL) }\end{array}$} \\
\hline \multirow{2}{*}{$\begin{array}{l}\text { RK (in straight track) } \\
(\mathrm{mm})\end{array}$} & -3 & 3 & -5 & 17 & -7 & 20 & -9 & 25 \\
\hline & -2 & 3 & -4 & 10 & \multicolumn{2}{|c|}{ not evaluated } & -5 & 20 \\
\hline \multirow{2}{*}{$\begin{array}{l}\mathrm{ZR} \\
(\mathrm{mm} / \mathrm{m})\end{array}$} & -3 & 3 & \multicolumn{2}{|c|}{ not evaluated } & -5 & 5 & -6 & 6 \\
\hline & -3 & 3 & -4 & 4 & \multicolumn{2}{|c|}{ not evaluated } & -5 & 5 \\
\hline \multirow{2}{*}{$\begin{array}{l}\mathrm{PK} \\
(\mathrm{mm})\end{array}$} & -3 & 3 & -13 & 13 & -15 & 15 & -20 & 20 \\
\hline & -3 & 3 & -15 & 15 & \multicolumn{2}{|c|}{ not evaluated } & -20 & 20 \\
\hline \multirow{2}{*}{$\begin{array}{l}\text { VP, VL } \\
(\mathrm{mm})\end{array}$} & -5 & 5 & -15 & 15 & -20 & 20 & -28 & 28 \\
\hline & -4 & 4 & -15 & 15 & \multicolumn{2}{|c|}{ not evaluated } & -20 & 20 \\
\hline \multirow{2}{*}{$\begin{array}{l}\text { SP, SL } \\
(\mathrm{mm})\end{array}$} & -5 & 5 & -15 & 15 & -18 & 18 & -20 & 20 \\
\hline & -5 & 5 & -15 & 15 & \multicolumn{2}{|c|}{ not evaluated } & -20 & 20 \\
\hline Measured parameter & \multicolumn{2}{|c|}{$\begin{array}{l}\text { Limit input } \\
\text { value }\end{array}$} & \multicolumn{2}{|c|}{$\begin{array}{l}\text { Operational } \\
\text { value }(A L)\end{array}$} & \multicolumn{2}{|c|}{$\begin{array}{l}\text { Operational } \\
\text { value (IL) }\end{array}$} & \multicolumn{2}{|c|}{$\begin{array}{c}\text { Limit operational } \\
\text { value (IAL) }\end{array}$} \\
\hline \multirow{2}{*}{$\begin{array}{l}\mathrm{ZK}_{3.0} \\
(\mathrm{~mm} / 3.0 \mathrm{~m} ; 1: \mathrm{n})\end{array}$} & 4.5 & $1: 667$ & 12 & $1: 250$ & 15 & $1: 200$ & 18 & $1: 167$ \\
\hline & $7.2^{*}$ & $1: 250^{*}$ & $7.2 *$ & $1: 250^{*}$ & \multicolumn{2}{|c|}{ not evaluated } & $10.8^{*}$ & $1: 167^{*}$ \\
\hline \multirow{2}{*}{$\begin{array}{l}\mathrm{ZK}_{6.0} \\
(\mathrm{~mm} / 6.0 \mathrm{~m} ; 1: \mathrm{n})\end{array}$} & \multicolumn{2}{|c|}{ not evaluated } & 16 & $1: 375$ & 20 & $1: 300$ & 24 & $1: 250$ \\
\hline & 18.8 & $1: 320$ & \multicolumn{2}{|c|}{ not evaluated } & \multicolumn{2}{|c|}{ not evaluated } & 24 & $1: 250$ \\
\hline \multirow{2}{*}{$\begin{array}{l}\mathrm{ZK}_{12.0} \\
(\mathrm{~mm} / 12.0 \mathrm{~m} ; 1: \mathrm{n})\end{array}$} & \multicolumn{2}{|c|}{ not evaluated } & 31 & $1: 387$ & \multirow{2}{*}{\multicolumn{2}{|c|}{\begin{tabular}{|c|c|}
34 & $1: 353$ \\
\multicolumn{2}{|c|}{ not evaluated }
\end{tabular}}} & 36 & $1: 333$ \\
\hline & note & luated & note & luated & & & 36 & $1: 333$ \\
\hline
\end{tabular}

Because of the ZSR requirements were measurements carried out until 31. 12. 2016 (MSO, PO1, PO2 a PO3) evaluated according to [5], [7]. Measurements carried out since 1. 1. 2017 (PO4) are evaluated according to [6], [8]. For the comparison of values, measurements of MSO, PO1, PO2 and PO3 were also evaluated according to [6], [8]. The limit values for standard deviations and quality numbers for section evaluation of the measured quantities are in table 2.

Table 2. Limit value of standard tolerances of variables and quality number for RP1. [7, 8]

\begin{tabular}{|c|c|c|c|c|c|c|c|c|c|}
\hline \multicolumn{5}{|c|}{ Limit input deviations } & \multicolumn{5}{c|}{ Limit operational deviations (IAL) } \\
\hline $\mathrm{SDV}_{\mathrm{RK}}$ & $\mathrm{SDV}_{\mathrm{PK}}$ & $\mathrm{SDV}_{\mathrm{VK}}$ & $\mathrm{SDV}_{\mathrm{SK}}$ & $\mathrm{QN}$ & $\mathrm{SDV}_{\mathrm{RK}}$ & $\mathrm{SDV}_{\mathrm{PK}}$ & $\mathrm{SDV}_{\mathrm{VK}}$ & $\mathrm{SDV}_{\mathrm{SK}}$ & $\mathrm{QN}$ \\
\hline 1.5 & 1.8 & 2.0 & 1.5 & 4.1 & 2.7 & 2.9 & 3.4 & 3.1 & 7.2 \\
\hline 1.5 & 1.8 & 2.0 & 1.5 & 4.1 & 2.9 & 2.9 & 3.4 & 2.9 & 7.2 \\
\hline
\end{tabular}

The overview of quality marks RK, PK, VK and SK (figure 1) and quality numbers (figure 2) of the monitored section displays stabilized parameter values. Among the MSO and PO1 and PO1 and PO2 measurements, the ZSR staff performed a set of corrective interventions that affected these values in the section and therefore it is not yet possible to fully determine the assumptions for further development of the quality of the section. Maintenance performed after MSO removed track geometry parameters errors before putting the track into operation. Post-PO1 corrective interventions were taken to eliminate mistakes due to an accident.

Within the MSO measurement, local errors (3x SL, 3x SP, 3x RK, 1x ZR) were detected, but after the next corrective intervention they were no longer detected in the operational evaluation. From the parameters whose quality mark enters the quality assessment of the section, the lowest quality has quality mark of track alignment $\mathrm{QM}_{\mathrm{SK}}$. 
The $\mathrm{QM}_{\mathrm{SK}}$ reaches slightly above the upper limit of the quality mark (2.00), which means the section quality in terms of track geometry is satisfactory. The PO3 rating was slightly higher than 2.00, but PO4 detected a decrease in $\mathrm{QM}_{\mathrm{SK}}$ below this value (according to [5] - [8]). Quality marks of other parameters achieve satisfactory values up to 0.70 .

The quality number of the monitored section is stabilized between to 1.97 to 2.11 (evaluated according to [5], [7]), respectively 1.96 to 2.02 (evaluated according to [6], [8]), which represents the satisfactory quality of the section, without the need to plan and carry out maintenance in the near term.

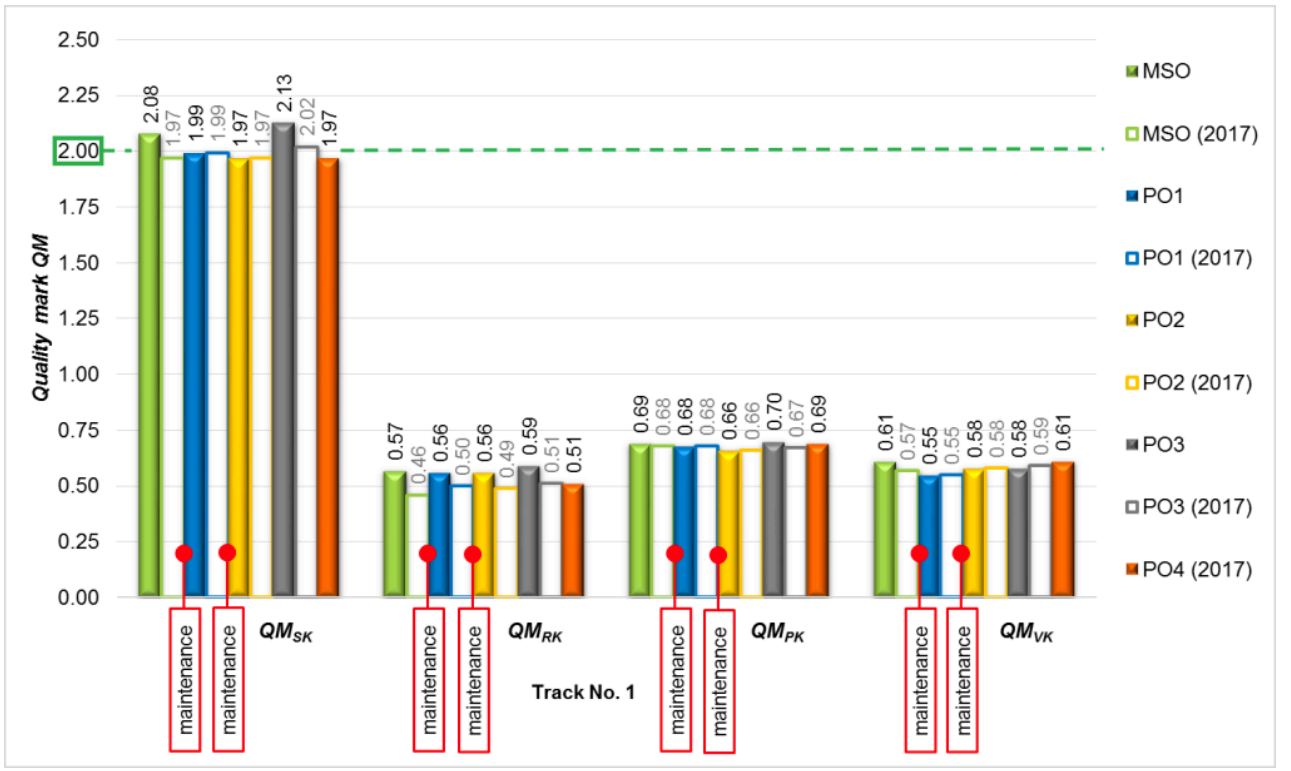

Fig. 1. Quality marks of the parameters of the track geometry - measurement carried out by measuring trolley $\mathrm{KRAB}^{\mathrm{TM}}-$ Light.

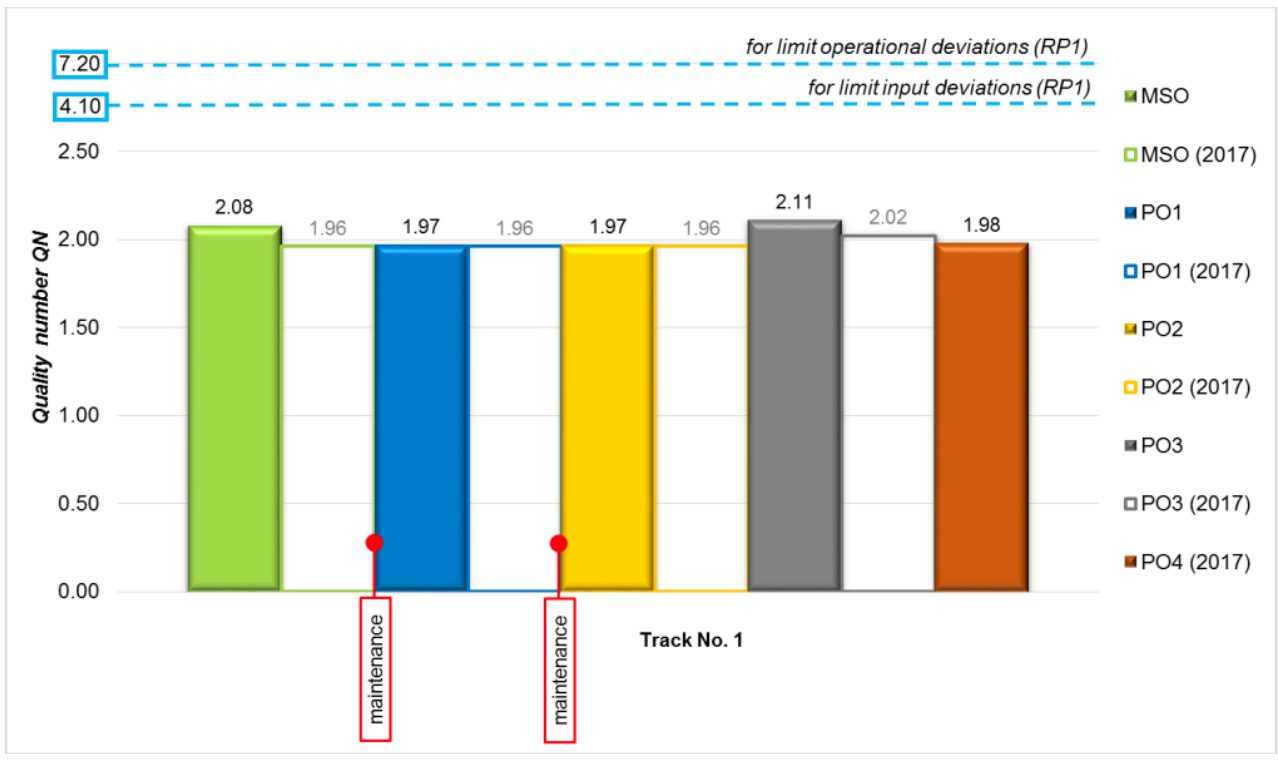

Fig. 2. Quality number of the experimental sections. 
In relation to traffic load of the structure, the transition areas between ballasted track and ballastless track (eg [9]) appear to be risky. For a detailed assessment of construction behaviour in the transition areas of the Lamac portal of length $18.020 \mathrm{~m}$ is processed deviation course overview of key parameters of track geometry involved to section assessment: RK, which is in KRAB 8.1 data represented by values RK_celk, PK (PK_celk), VP /VL/ (VP_dyn_P /VL_dyn_L/), SP /SL/ (SP_dyn_P / SL_dyn_L/) - figures 3 to 8 .

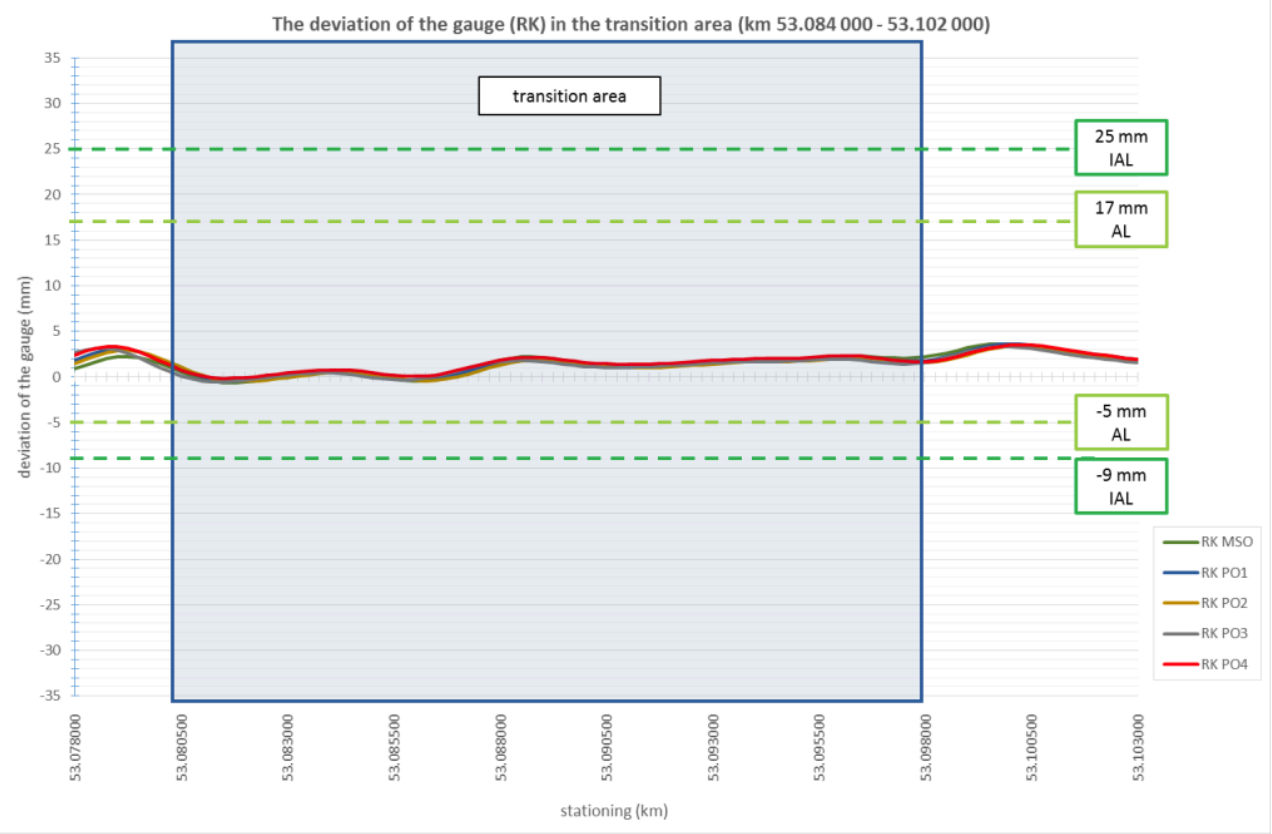

Fig. 3. The deviation of the gauge in the transition area.

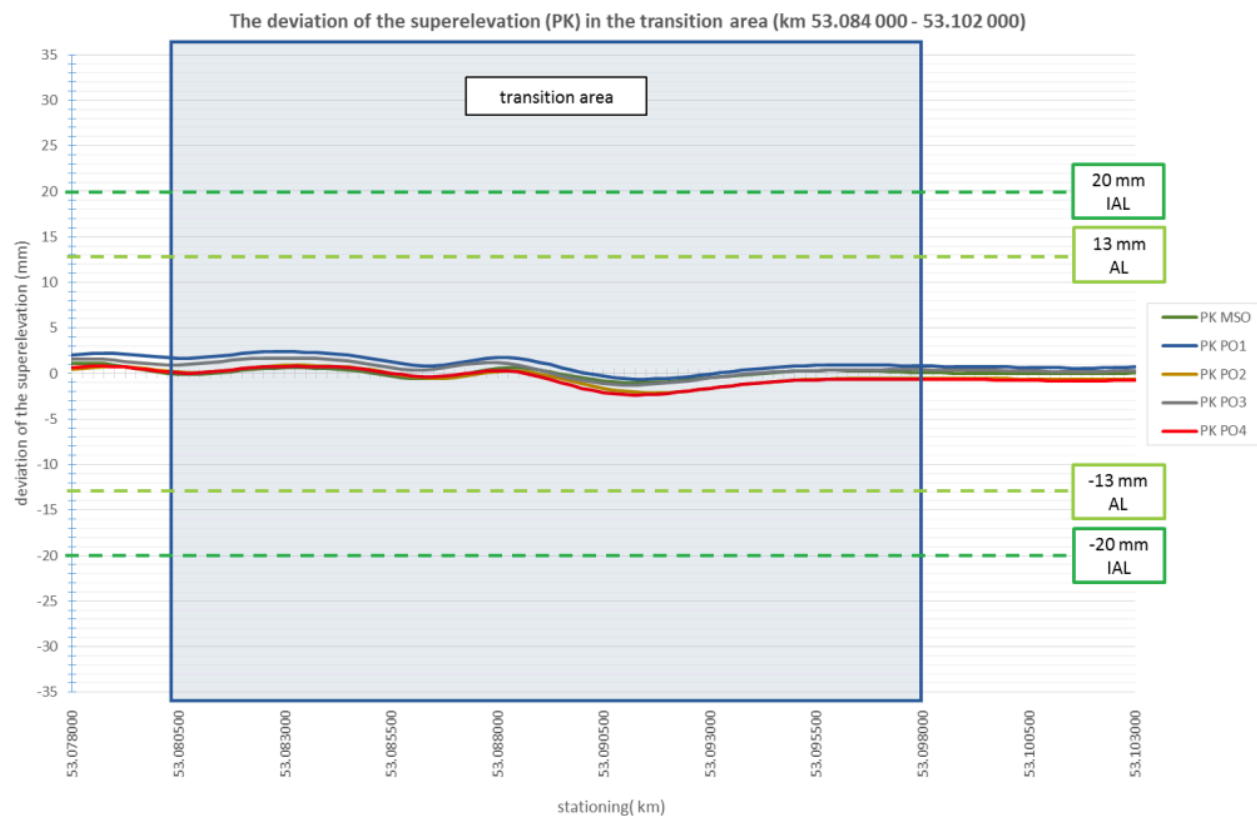

Fig. 4. The deviation of the superelevation in the transition area. 
Deviations of PK parameter measured in PO4 have a value of less than about $2 \mathrm{~mm}$ compared to deviations in PO1, but given the almost parallel curve behaviour, it can be assumed that the change is a combination of the impact of track consolidation after corrective intervention and measurement uncertainty of the measuring device calibrated before measurement MSO and before measurement PO4.

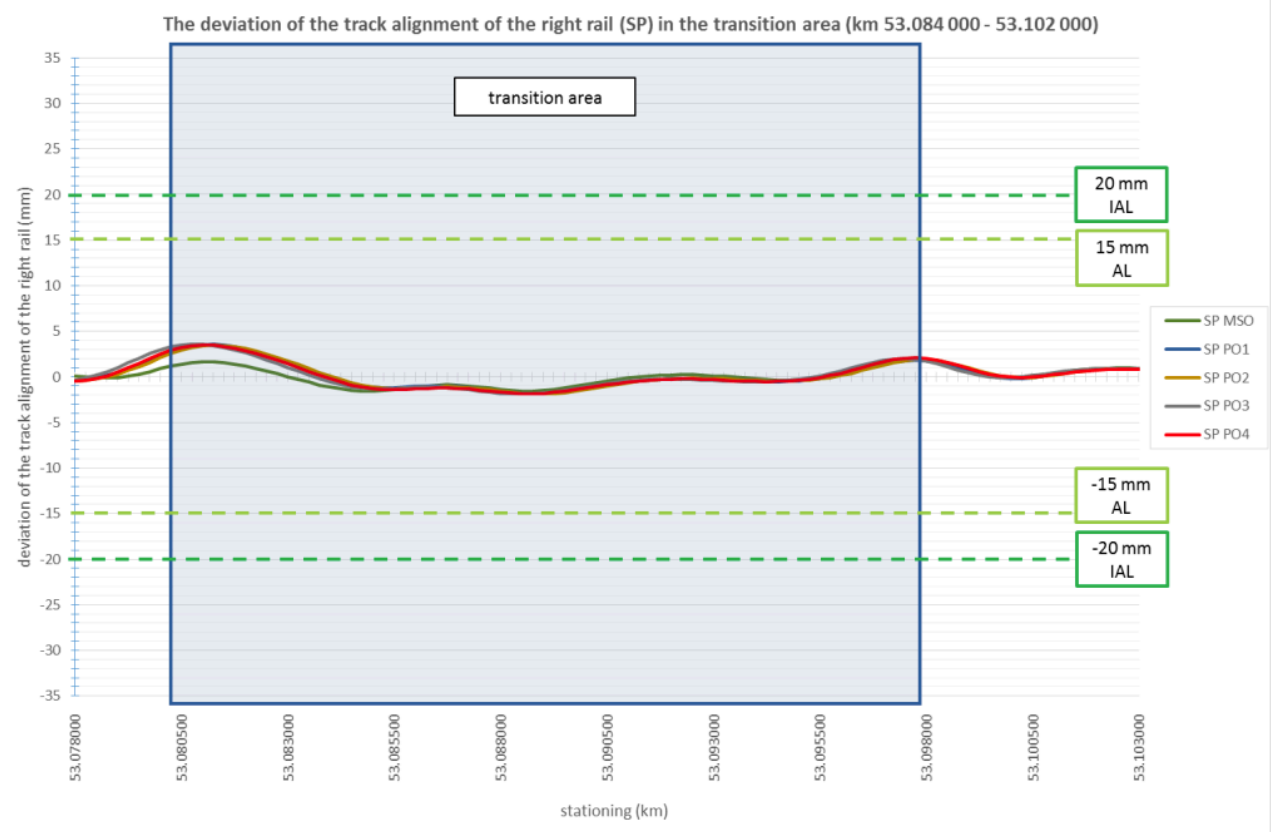

Fig. 5. The deviation of the top level of the right rail in the transition area.

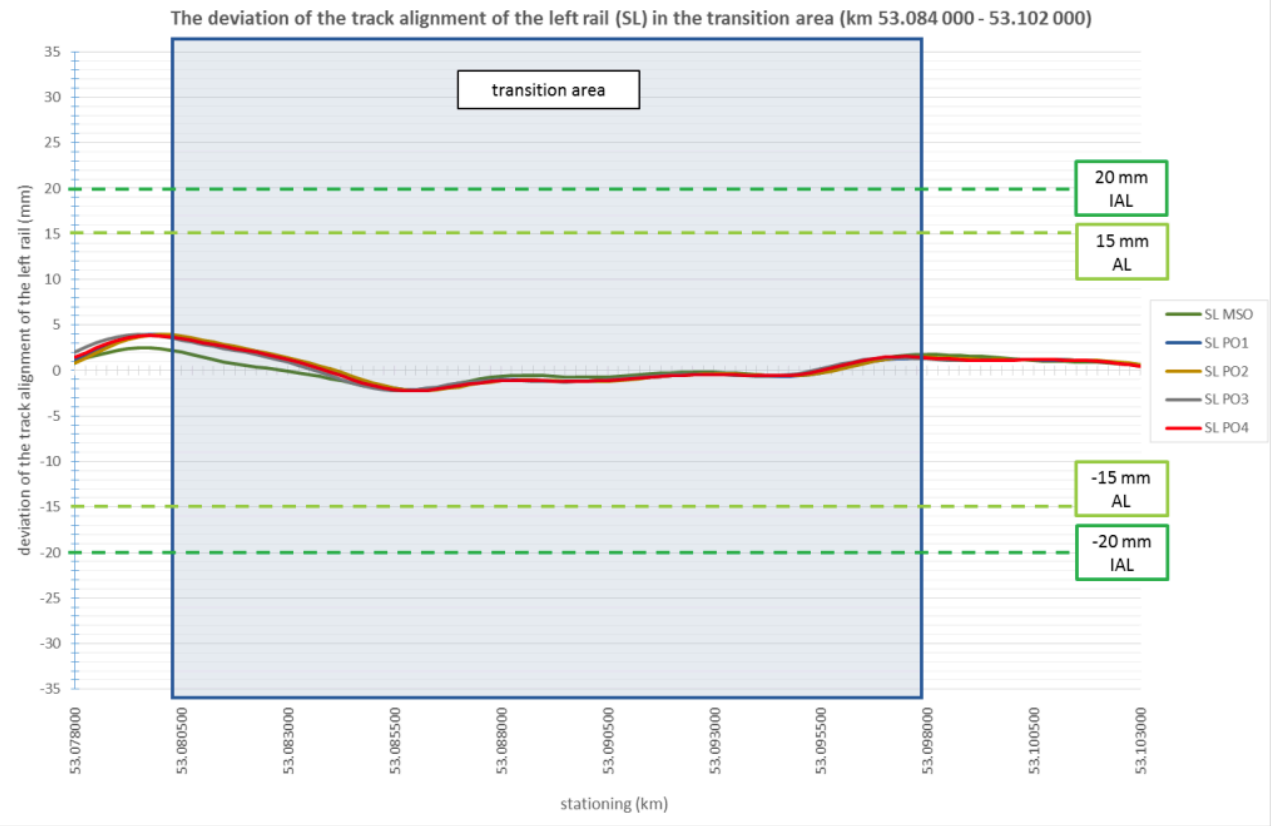

Fig. 6. The deviation of the top level of the left rail in the transition area. 


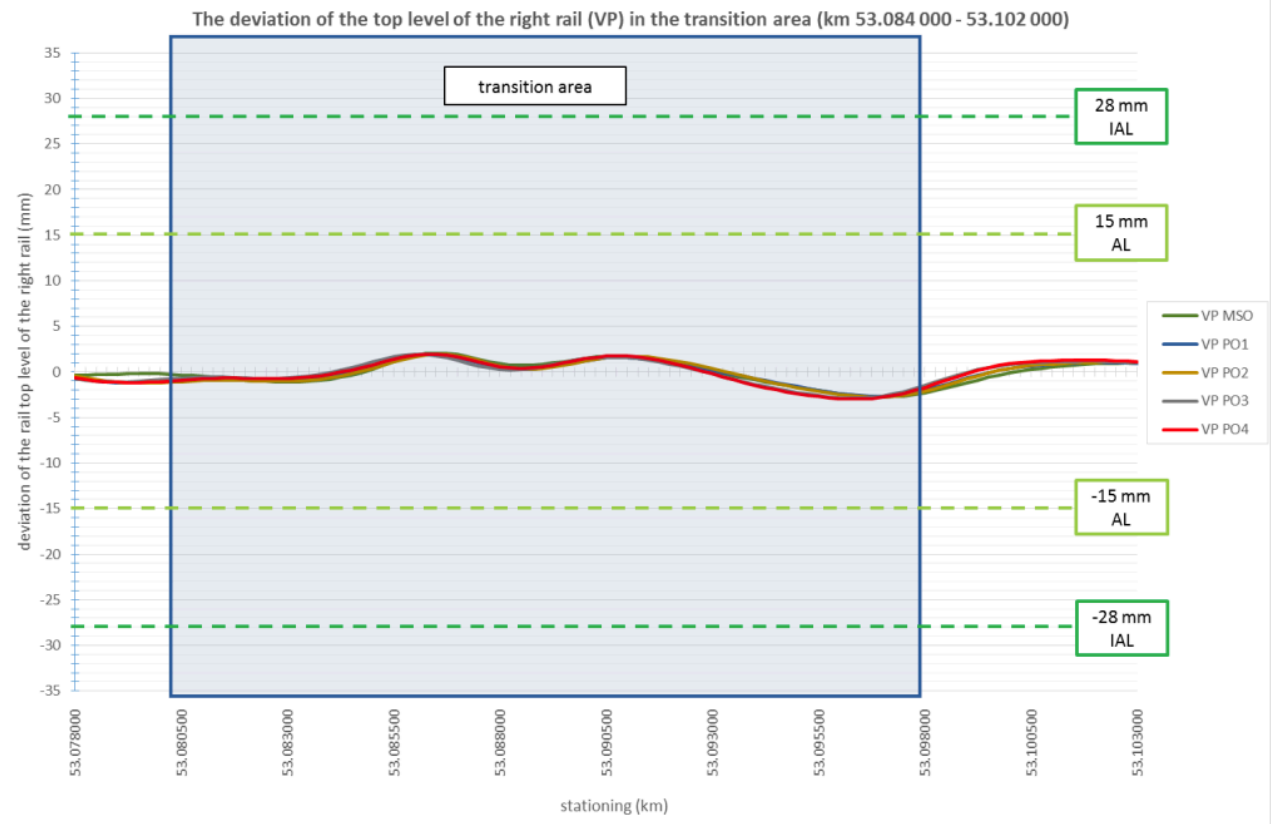

Fig. 7. The deviation of the track alignment of the right rail in the transition area.

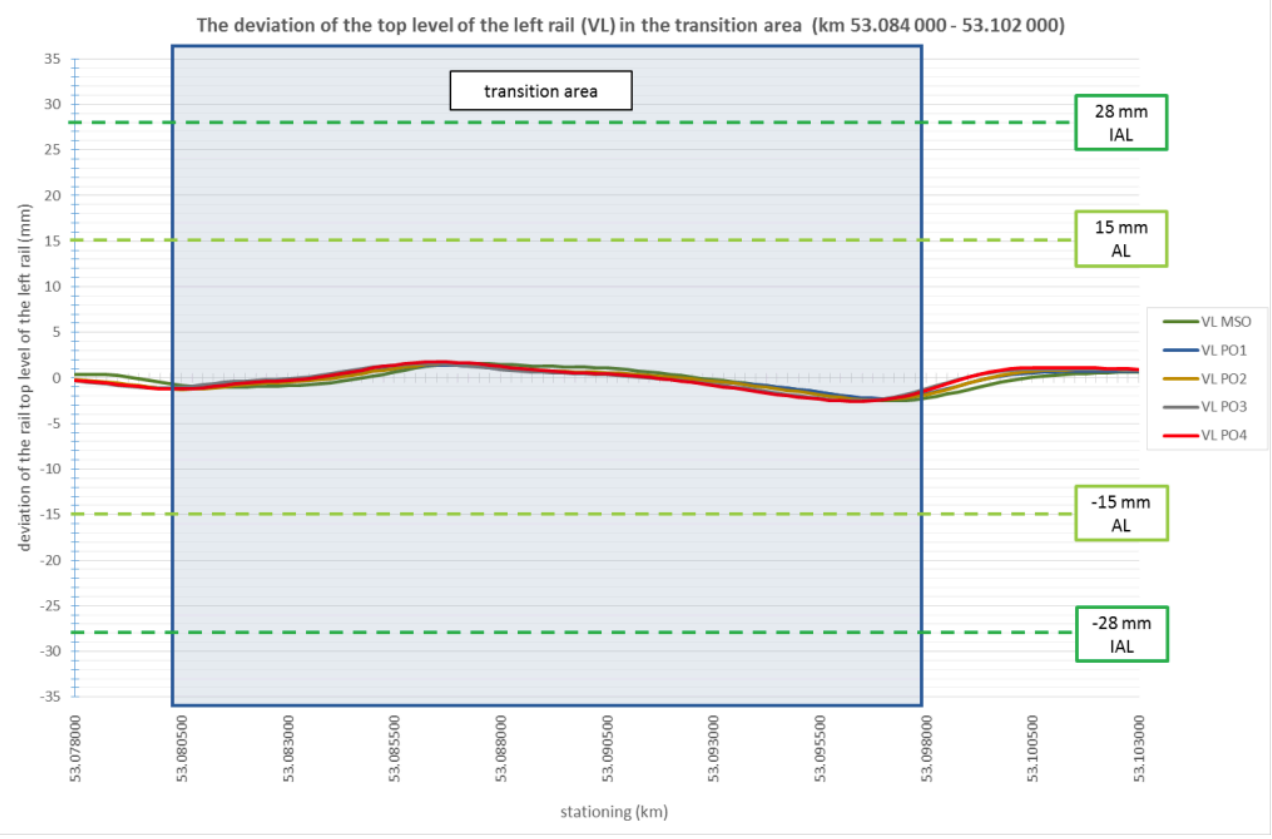

Fig. 8. The deviation of the track alignment of the left rail in the transition area.

\section{Conclusions}

Monitoring of the track geometry parameters of the track on the KZSTH experimental section in the Bratislava tunnel No. 1 confirms the sustained state at the required level of quality. Three quality marks (RK, PK, VK) of the four evaluated variables affecting the 
section quality number reach $35 \%$ of the maximum value of the quality mark (2.00) in the interval of satisfactory evaluation of the track geometry of the section. Marks of the quality of the remaining quantity (SK), within the measurements MSO, PO1, PO2 and PO3, approached or exceeded the value of 2.00 (in the interval $98.5 \%$ to $106.5 \%$ of this value), but in last realized measurement (PO4) again fell to the range of satisfactory evaluation (value 1.97). The section quality number is $27.2 \%$ to $29.3 \%$ of the maximum permissible value of the quality number (7.2) for the sectional evaluation of the measured quantities according to the immediate action limit (IAL). The satisfactory quality of the whole section is also achieved by the high length of the ballastless track construction (approx. $94 \%$ ), where track geometry quantities almost do not change.

From the evaluation of the exact deviation course of the values RK, PK, SP (SL) and VP (VL) from the projected values, we can state that there are no changes in the track geometry parameters in the transition area of the Lamac portal. The graphical representation of the deviations in the transition area $(\mathrm{km} 53.080$ to $\mathrm{km} \mathrm{53.098)} \mathrm{shows}$ a stabilized deviation course (maximum values are within $\pm 5 \mathrm{~mm}$ for all variables) over the entire length of the transition area, without the tendency to quality degradation. These positions are retained since the construction was put into operation and also after maintenance carried out after measurement MSO for all evaluated variables. The railway track superstructure in the transition area, according to the results obtained so far, appears to be suitable for a track with a track speed $(60 \mathrm{kmph})$ assigned to RP1.

The paper contains results of the grant VEGA 1/0275/17 "Application of numerical methods to define the changes of geometrical track position".

\section{References}

1. E. Darr, W. Fiebig, W. Feste Fahrbahn. Konstruktion und Bauarten für Eisenbahn und Straßenbahn (Eurailpress Tetzlaff-Hestra GmbH\&Co. KG, Hamburg, 2006)

2. O. Plasek, P. Zverina, R. Svoboda, M. Mockovciak Railway Constructions. Railway Subgrade and Superstructure (Akademicke nakladatelstvi CERM, Brno, 2014) (in Czech)

3. L. Izvolt, M. Smalo, J. Malchova The Quality Evaluation of the Ballastless Track Construction in the Area of Bratislava Tunnel No. 1, MATEC Web of Conferences 86, 05001 (2016)

4. Technical Standard STN 73 6360-1 Railway Applications. Track. Part 1: Geometrical Position Arrangement of $1435 \mathrm{~mm}$ Gauge Railways, (2015) (in Slovak)

5. Technical Standard STN 736360 (1999) Track Alignment Design and Track Geometry of Normal-gauge Tracks (1999) and Amendment 1 (2002) (in Slovak)

6. Technical Standard STN 73 6360-2 Railway Applications. Track. Part 2: Acceptance of Construction Works, Maintenance Works and Assessment of Service Condition Track Gauges 1435 mm (2015) (in Slovak)

7. Regulation of ZSR SR 103-7 (S) Measurement and Evaluation of Track Geometry by Measuring Trolley KRAB (2008) (in Slovak)

8. Regulation of ZSR SR 103-7 (TS) Measurement and Evaluation of Track Geometry of Gauge $1435 \mathrm{~mm}$ and $1520 \mathrm{~mm}$ by Measuring Trolley KRAB (2016) (in Slovak)

9. M. Smalo The Use of Ballastless Track Monitoring in its Maintenance (Dissertation) (University of Zilina, Faculty of Civil Engineering, 2017) (in Slovak) 